\title{
Autofluorescence Spectroscopy and Imaging II: A Special Issue Aimed to Promote Optically Based Studies on Biological Substrates
}

Anna C. Croce ${ }^{1,2}$ (D)

check for updates

Citation: Croce, A.C.

Autofluorescence Spectroscopy and Imaging II: A Special Issue Aimed to Promote Optically Based Studies on Biological Substrates. Photochem 2022, 2,1-4. https://doi.org/10.3390/ photochem 2010001

Received: 14 December 2021 Accepted: 23 December 2021 Published: 29 December 2021

Publisher's Note: MDPI stays neutral with regard to jurisdictional claims in published maps and institutional affiliations.

Copyright: (C) 2021 by the author. Licensee MDPI, Basel, Switzerland. This article is an open access article distributed under the terms and conditions of the Creative Commons Attribution (CC BY) license (https:// creativecommons.org/licenses/by/ $4.0 /)$.
1 Institute of Molecular Genetics, Italian National Research Council (CNR), Via Abbiategrasso 207, I-27100 Pavia, Italy; croce@igm.cnr.it; Tel.: +39-0382-986-428

2 Department of Biology \& Biotechnology, University of Pavia, Via Ferrata 9, I-27100 Pavia, Italy

The Journal Molecules, in particular the Photochemistry Section, and the younger Journal Photochem are active in promoting the advances and practical applications based on the interaction of light with the various biological substrates from both animal and vegetal systems [1]. These investigations belonging to the photobiology branch of natural sciences are increasingly addressing autofluorescence properties of biological substrates, with their implications in fields ranging from environment and ecology to food production, biomedicine, and diagnosis in the clinics. In this view, a contribution to the progress of these fields of studies has been already provided by the first edition of the Special Issue entitled "Autofluorescence Spectroscopy and Imaging", in Molecules. As regards vegetables, the autofluorescence of chlorophyll was proposed as a direct indicator of the growth of algae biomass, with interesting perspectives for the improvement of industrial applications (Takahashi) [2]. The role of chlorophyll autofluorescence as a biomarker of the health state of leaves and plants was also highlighted by a comprehensive review on the autofluorescence of vegetables with the various endogenous fluorophores involved. Another example regarded lignin, with its autofluorescence highlighted as exploitable for the direct analysis of wood, for phenotyping purposes, or to assess the conditions of wood formation [3].

Regarding animal biosystems, the biomedical field received major attention. A review based on a systematic search in the MEDLINE database and Cochrane Library reported on the clinical autofluorescence application for diagnostic purposes in extra-ophthalmic tissues [4]. With particular reference to thyroid surgery, the near-infrared (NIR) spectroscopy is within the intraoperative techniques applied to discriminate and preserve the healthy parathyroid tissue and its hormonal functions in the regulation of calcium homeostasis [5]. In this context, the intraoperative assistance of the NIR autofluorescence imaging in thyroid and parathyroid surgery was explored on the basis of both the literature and the Author's 5 -year experience, indicating effective support of the technique in the discrimination of two glands [6]. Interestingly, in the same study, suggestions were provided on the nature of the biomolecules acting as endogenous fluorophores in the NIR. The similarities between the parathyroid, pancreas, and adrenal medulla suggested a likely relationship with the engagement in hormone production, providing perspectives to translate NIR image diagnosis procedures from thyroid/parathyroid to other endocrine glands. The aim to investigate the biometabolic mechanisms involved in autofluorescence changes in pathology gave rise to an interesting advance from the innovative study on the direct relationship between the autofluorescence of colon neoplastic tissue, from the clinical endoscopy or surgery, and the activation status of cell genes, in particular p53 and p16, engaged in the regulation of cell proliferation [7]. In the experimental biomedicine with a preclinical connotation, the value of autofluorescence spectroscopy at different excitation wavelengths was also suggested as a tool to discriminate fatty from the healthy liver in an animal model [8]. Experimental rat 
livers were also used to investigate serum autofluorescence spectroscopy to assess changes in fluorescing fatty acids as biomarkers of the organ injury when submitted to ischemia and reperfusion [9]. The use of models in solution and of cultured human keratinocytes allowed the observation of a remarkable rising of the red $(>650 \mathrm{~nm})$ autofluorescence emission following UV irradiation. This event was ascribed to the induction of oxidative damage and consequent accumulation of oxidative products, enforcing the value of their red emission as a cell and tissue biomarker of accumulation of oxidative stress events [10].

These results moved to the launch of a second edition of the Special Issue entitled "Autofluorescence Spectroscopy and Imaging II", involving jointly the Journals Molecules and Photochem. A review published in Photochem aims to further promote the interest of the scientific community in the wide-ranging potential of light-based events involving biological substrates [11]. The most recurrent and studied biomolecules with natural fluorescing properties or able to interact with light in any other way have been highlighted, with reference to their manifold functions in microorganisms, plants, fungi, and animals of various taxonomic degrees, up to biomedicine. The most relevant biological, ecological, nutritional, and biomedical issues have been considered, with attention also to their interlaced relevance to human health, as a hopeful attracting and inspiring source for the scientific community, able to stimulate new investigations and advances in the research fields based on the interaction of light-biological substrates.

The papers thus far collected have contributed to covering additional autofluorescence fields of interest, as compared with the first Special Issue. Two review papers have been published in Photochem, both of them dealing with light-based procedures for the quality control of food. More specifically, recent advances have been critically revised with reference to fluorescence spectroscopy applications in the discrimination between truly fresh or frozen-thawed meat and fish products [12]. The paper underscores the continuously increasing number of published papers on the matter, underlining the growing attention to the potential and improvement of the optical procedures for the direct, real-time analysis and control of food. The most pertinent endogenous fluorophores and fluorescence techniques applied-namely. 2D or excitation-emission matrices spectroscopy, have been also described, along with reflections on the importance of the interdisciplinary cooperation between researchers on spectroscopy and data processing, industry, and regulatory authorities in the application of light-based procedures in fraud prevention in the food industry. Similar findings emerge from the review on the application of hyperspectral imaging (HSI) to detect adulteration of food [13]. Different approaches in the use of HIS have been underlined, suitable to set up applications for the control of the quality of different categories of food, including herbs, species, oils and cereals, fish, meat, milk, and related products. The aim of the review was also to bring to attention the importance of the integration and implementation of visible fluorescence HSI with Raman HIS, as well as to the necessity to improve databases and technology, in terms of both hardware and image pre- and processing algorithms, and to customize the procedures to enhance the performance of their routine use in food control.

More pertinent to biomedicine are the more variegated, original papers published in Molecules thus far. Basic research studies have proposed innovative uses of fluorescing probes, in terms of both endogenous fluorophores or their synthetic derivatives. As to the latter kind of products, a new coumarin-acridone fluorescent derivative has been validated in cultured cell and zebrafish models as an in vivo, low-toxic fluorescent intracellular probe of $\mathrm{Fe} 3+$. Given the essential role of iron in many physiological functions of biological systems, as well as the negative and pathological issues deriving from its excessive or insufficient intake, the new fluorescing probe provides interesting perspectives to improve related investigations in biomedicine [14].

On the other hand, the UV-induced autofluorescence of endogenous fluorophores pyridine nucleotides NADH and NADPH, commonly known for a long time, has been used as a real-time biomarker in situ, to investigate the response of the pathways of energy metabolism and antioxidant defense to changes in environmental atmospheric pressure. 
The original investigation performed on a Saccharomyces cerevisiae (baker's yeast) model, also in the presence of respiratory inhibitors, has provided new insights to improve the studies on cell energy metabolism, i.e., mitochondrial functionality, cell redox state, and production of reactive oxygen species in high-pressure conditions, with perspectives for applications in food production and agriculture [15]. Additionally, the autofluorescence of natural bilirubin has been exploited to investigate its role as a hormonal agent, with the specific aim to characterize its binding to the nuclear receptor peroxisome proliferatoractivated receptor- $\alpha$ (PPAR $\alpha)$, engaged in the regulation of genes in the control adiposity. The study, taking advantage of the autofluorescence excitation and emission spectra of bilirubin as intrinsic self-biomarker, has allowed the assessment of the amino acids responsible for the specific binding of bilirubin to the ligand-binding pocket in the PPAR $\alpha$, providing additional awareness on bilirubin as a multitasking molecule with many mechanisms of action [16]. The infrared spectral properties of some biochemical components of microorganisms, in turn, have been exploited to characterize and discriminate biofilms of microbial pathogens. The use of a synchrotron macro-ATR-FTIR microspectroscopy technique has allowed the differentiation of biofilms of Gram-positive and Gram-negative pathogenic bacteria, respectively, a drug-resistant Staphylococcus aureus and Pseudomonas aeruginosa, and the yeast Candida albicans. The discrimination ability has been ascribed mostly to the changes in the polysaccharide signal in the IR spectrum, besides the spectral signals from other components such as lipids and amines, leading to propose the procedure to improve the studies on pathogen biofilms [17].

Finally, a study on the irradiation biological effects of a femtosecond laser has demonstrated the possibility to obtain a specific localized ionization of biological substrate, similarly to what is obtained by ionizing radiation, as proved by the immunocytochemical localization of the induction of foci of DNA repair proteins. While indicating the possibility to use light irradiation instead of ionizing radiation, the study raises awareness of possible hazardous effects in the biomedical use of femtosecond laser radiation [18].

In summary, the second Special Issue on autofluorescence has been successful in recruiting innovative contributions on the various aspects and applications of the events following the light interaction with biological substrates. Notably, these works share a common attention to the biochemical identity of the endogenous fluorophores, from the most classical compounds exploited for innovative kinds of investigations to the new candidates under identification. The consequent contribution in the improvement of the knowledge on the biometabolic basis responsible for the properties of autofluorescence signals and of their changes is a surely valid support to the development of innovative analytical applications.

Funding: This research received no external funding.

Acknowledgments: Waiting for the requested last contributions before the closure of the Special Issue, I would like to thank all the authors, for the work provided with their contribution, the academic editors and reviewers, for the precious support helping to select and improve the valuable published papers.

Conflicts of Interest: The author declares no conflict of interest.

\section{References}

1. Croce, A.C. Photobiology and Endogenous Fluorophore Based Applications, from Natural Environment to Biomedicine to Improve Human Life. Molecules 2020, 25, 5707. [CrossRef] [PubMed]

2. Takahashi, T. Routine Management of Microalgae Using Autofluorescence from Chlorophyll. Molecules 2019, 24, 4441. [CrossRef] [PubMed]

3. Donaldson, L. Autofluorescence in Plants. Molecules 2020, 25, 2393. [CrossRef] [PubMed]

4. Wizenty, J.; Schumann, T.; Theil, D.; Stockmann, M.; Pratschke, J.; Tacke, F.; Aigner, F.; Wuensch, T. Recent Advances and the Potential for Clinical Use of Autofluorescence Detection of Extra-Ophthalmic Tissues. Molecules 2020, 25, 2095. [CrossRef] [PubMed]

5. Baj, J.; Sitarz, R.; Łokaj, M.; Forma, A.; Czeczelewski, M.; Maani, A.; Garruti, G. Preoperative and Intraoperative Methods of Parathyroid Gland Localization and the Diagnosis of Parathyroid Adenomas. Molecules 2020, 25, 1724. [CrossRef] [PubMed] 
6. Ladurner, R.; Lerchenberger, M.; al Arabi, N.; Gallwas, J.K.S.; Stepp, H.; Hallfeldt, K.K.J. Parathyroid Autofluorescence-How Does It Affect Parathyroid and Thyroid Surgery? A 5 Year Experience. Molecules 2019, 24, 2560. [CrossRef] [PubMed]

7. Moriichi, K.; Fujiya, M.; Kobayashi, Y.; Murakami, Y.; Iwama, T.; Kunogi, T.; Sasaki, T.; Ijiri, M.; Takahashi, K.; Tanaka, K.; et al. Autofluorescence Imaging Reflects the Nuclear Enlargement of Tumor Cells as Well as the Cell Proliferation Ability and Aberrant Status of the P53, Ki-67, and P16 Genes in Colon Neoplasms. Molecules 2019, 24, 1106. [CrossRef] [PubMed]

8. Valor, A.; Arista Romeu, E.J.; Escobedo, G.; Campos-Espinosa, A.; Romero-Bello, I.I.; Moreno-González, J.; Fabila Bustos, D.A.; Stolik, S.; de La Rosa Vázquez, J.M.; Guzmán, C. Study of Methionine Choline Deficient Diet-Induced Steatosis in Mice Using Endogenous Fluorescence Spectroscopy. Molecules 2019, 24, 3150. [CrossRef] [PubMed]

9. Croce, A.C.; Ferrigno, A.; Berardo, C.; Bottiroli, G.; Vairetti, M.; di Pasqua, L.G. Spectrofluorometric Analysis of Autofluorescing Components of Crude Serum from a Rat Liver Model of Ischemia and Reperfusion. Molecules 2020, 25, 1327. [CrossRef] [PubMed]

10. Semenov, A.N.; Yakimov, B.P.; Rubekina, A.A.; Gorin, D.A.; Drachev, V.P.; Zarubin, M.P.; Velikanov, A.N.; Lademann, J.; Fadeev, V.V.; Priezzhev, A.V.; et al. The Oxidation-Induced Autofluorescence Hypothesis: Red Edge Excitation and Implications for Metabolic Imaging. Molecules 2020, 25, 1863. [CrossRef] [PubMed]

11. Croce, A.C. Light and Autofluorescence, Multitasking Features in Living Organisms. Photochem 2021, 1, 67-125. [CrossRef]

12. Hassoun, A. Exploring the Potential of Fluorescence Spectroscopy for the Discrimination between Fresh and Frozen-Thawed Muscle Foods. Photochem 2021, 1, 247-263. [CrossRef]

13. Tümay Temiz, H.; Ulas, B.U. A Review of Recent Studies Employing Hyperspectral Imaging for the Determination of Food Adulteration. Photochem 2021, 1, 125-146. [CrossRef]

14. Huang, J.; Yan, Z.; Qiu, P.; Mo, Y.; Cao, Q.; Li, Q.; Huo, L.; Zhao, L. A New Coumarin-Acridone Compound as a Fluorescence Probe for $\mathrm{Fe}^{3+}$ and Its Application in Living Cells and Zebrafish. Molecules 2021, 26, 2115. [CrossRef]

15. Heidelman, M.; Dhakal, B.; Gikunda, M.; Silva, K.P.T.; Risal, L.; Rodriguez, A.I.; Abe, F.; Urayama, P. Cellular NADH and NADPH Conformation as a Real-Time Fluorescence-Based Metabolic Indicator under Pressurized Conditions. Molecules 2021, $26,5020$. [CrossRef]

16. Gordon, D.M.; Hong, S.H.; Kipp, Z.A.; Hinds, T.D. Identification of Binding Regions of Bilirubin in the Ligand-Binding Pocket of the Peroxisome Proliferator-Activated Receptor-A (PPARalpha). Molecules 2021, 26, 2975. [CrossRef]

17. Cheeseman, S.; Shaw, Z.L.; Vongsvivut, J.; Crawford, R.J.; Dupont, M.F.; Boyce, K.J.; Gangadoo, S.; Bryant, S.J.; Bryant, G.; Cozzolino, D.; et al. Analysis of Pathogenic Bacterial and Yeast Biofilms Using the Combination of Synchrotron ATR-FTIR Microspectroscopy and Chemometric Approaches. Molecules 2021, 26, 3890. [CrossRef] [PubMed]

18. Zalessky, A.; Fedotov, Y.; Yashkina, E.; Nadtochenko, V.; Osipov, A.N. Immunocytochemical Localization of XRCC1 and ГH2AX Foci Induced by Tightly Focused Femtosecond Laser Radiation in Cultured Human Cells. Molecules 2021, 26, 4027. [CrossRef] [PubMed] 